\title{
EDITORIAL
}

\section{Promoting a future without tobacco: also a continuing task for respiratory medicine in Europe}

\author{
P. Tønnesen*, P.A. Vermeire**
}

The eleventh World Conference on Tobacco or Health in Chicago, USA with approximately 5,000 delegates, was held during the second week of August 2000. The authors believe that many of the attendants experienced a feeling of "recharging the batteries" as a result of participating in this conference. The value of a conference which gathers people playing different roles in the fight against tobacco is that personal scientific views are put into a more holistic perspective, showing that science, legislation and politics have to work hand-in-hand to reduce the harmful effects of tobacco. In recognition of the importance of this conference the editors of the Journal of the American Medical Association and the British Medical Journal have released thematic issues of their journals concerning tobacco use $[1,2]$. The present contribution to the European Respiratory Journal is an update on what is going on scientifically and politically in the field of tobacco control.

Tobacco is a global product and a global problem. Smoking contributes to a death rate in excess of four million people worldwide and this is suspected to increase to 10 million by the year 2030, with the majority of this increase occurring in the Third World countries. Because of the globalization of trade, marketing and information, the actions of the individual countries in tobacco control cannot be anything but ineffective.

\section{World Health Organization convention on tobacco control}

At the Conference, the director of the World Health Organisation (WHO), G.H. Brundtland, presented the Framework convention on tobacco control. This convention is an "international legal agreement concluded between states in written form and governed by international law" and, for those countries signing it, it will be binding to improve transnational tobacco control and cooperation. "The guiding principle..... is to make it clear that tobacco is an important contributor to inequity in health in all societies; as a result of the addictive nature and the health damage associated with tobacco use it must be considered as a harmful commodity; the public has a right to be fully

*Dept of Pulmonary Medicine, Gentofte University Hospital, Copenhagen, Denmark. **Dept of Respiratory Medicine, University of Antwerp (UIA), Antwerp, Belgium.

Correspondence: P. Tønnesen, Dept of Pulmonary Medicine Y, Gentofte University Hospital, 2900 Hellerup, Denmark. Fax: 4539777628. informed about the health consequences of using tobacco products; and the health sector has a leading responsibility to combat the tobacco epidemic, but success cannot be achieved without the full contribution of all sectors of the society".

The state parties could agree to include the following objectives: protection of children and adolescents from active and passive smoking; promoting smoke-free environments; promoting healthy tobacco-free economics, especially, preventing smuggling; strengthening women's leadership in tobacco control; enhancing the capacity of all member states in tobacco control and exchange of information at national and international levels, and protecting vulnerable communities including indigenous people [3].

The most effective elements in the antitobacco policy are increases in the tax on cigarettes, a total ban on cigarette advertisements, no-smoking policies in work and public places, and prominent warnings on cigarette packages. As an example it has been observed that a $10 \%$ increase in the price of cigarettes would reduce smoking by $4 \%$ in high-income and by $8 \%$ in low-income countries. It seems that this effect is especially effective in teenagers, low-income groups and in those with a low educational background [4].

However, the opponent in this battle is very strong, the tobacco industries yearly income is more than $\$ 400$ billion and it is only exceeded by the gross national product (GNP) in 15 countries. Consequently, elements with less documented efficacy should, according to the WHO, be used, including counter advertisements, regulation of tobacco products, prohibition of sponsorships from tobacco companies for art, music or sport events.

\section{Interventions to prevent youngsters from smoking}

The two cornerstones in reducing the number of smokers are both the prevention of the recruitment of smokers among young subjects, and smoking cessation among smokers. The tobacco industry has been targeting teenagers in their campaigns and also cigarettes have been changed as to be a better "starter" product. The recent increase in smoking among young adults is both alarming and disappointing. A recent national cross-sectional population survey, carried out in the USA and including 17,185 adolescents aged 15-17 yrs, showed an association between their smoking habits and household and workplace smoking restrictions. Adolescents living in a smoke-free home were $74 \%$ as likely to be smokers as those living in homes with exposure to cigarette smoke. Youngsters 
working in smoke-free workplaces were $68 \%$ as likely to be smokers compared with those working in places without restrictions. Therefore, the emphasizes on reducing smoking in adolescents cannot simply be placed on encouraging smoke-free household, but a broader approach to the entire population is required, e.g. instituting smokefree workplaces, is more effective [5].

In another cross-sectional USA survey, comprising 17,287 high school students, it was found that restrictions on smoking at home were associated with a later uptake of the smoking habit and lower smoking prevalence. The same findings were reported for more persuasive restrictions on smoking in public. School smoking bans led to lower smoking rates and of being in an earlier stage of smoking uptake, only when the ban was strongly enforced i.e. most students obeyed the rule [6].

A National Tobacco Control programme, aimed at middle and high school students in Florida, showed a reduction in youth tobacco use. This two-year programme of $\$ 120$ million was funded as part of the $\$ 11$ billion legal settlement between the State of Florida and the tobacco industry. The programme was comprehensive, youth-driven with multiple approaches towards education, marketing, prevention and coupled with an enforcement campaign, empowering youths to live tobacco-free. After 2 yrs current cigarette use had dropped from $18.5 \%$ to $11.1 \%$ among middle school students and from $27.4 \%$ to $22.6 \%$ among high school students [7]. European countries can thus learn from the comprehensive tobacco control programmes covering entire states in the USA, such as Arizona, Massachusetts and California [8, 9].

Acquiring grants for tobacco control activities is fundamental. The settlement agreement between 46 state attorney generals and the USA tobacco companies amounted to $\$ 246$ billion. However, only eight states have allocated enough money to run comprehensive tobacco control programmes. Thus, if similar agreements were achieved in Europe, it would be essential that the funds from such tobacco settlements should be used for tobacco control purposes only.

\section{Health effects of stopping smoking}

The adverse health effects related to smoking are the main reasons for healthcare workers to want to reduce tobacco use. They would not go to all the trouble in trying to persuade smokers to quit, if it were not to protect the individual smoker from serious diseases, such as lung cancer, chronic obstructive pulmonary disease (COPD) and diseases resulting from arteriosclerosis.

Tobacco has been used in Europe for approximately $500 \mathrm{yrs}$, but it was only in 1950 that the health hazards related to the smoking of cigarettes was first documented, especially its relation to lung cancer $[10,11]$. Smokers lose on average 7.5 yrs of life compared with never smokers, which was shown by the observational study of 34,439 British doctors, followed during 40 yrs. In middle and early old age the annual mortality among smokers was double that of nonsmokers [12].

New evidence for the beneficial effects of stopping smoking on the risk of lung cancer was published in a recent issue of the British Medical Journal [1]. Results from two case-control studies in the UK, centered around
1950 and 1990, showed that in subjects who stop smoking the risk of lung cancer is considerably decreased; for males who stopped at ages 60, 50, 40 and 30, the cumulative risk of lung cancer at 75 yrs of age was $10 \%$, $6 \%, 3 \%$ and $2 \%$ respectively, compared with the risk in those males and females who continued to smoke, $(16 \%$ and $10 \%$ respectively). This study adds to the current knowledge that stopping smoking before middle age removes $>90 \%$ of the risk attributable to tobacco. Mortality in the first half of the 21 st century will thus, be much more affected by the number of adult smokers who stop than by the number of adolescents who start, since the latter will only affect mortality in the middle or second half of the $21 \mathrm{st}$ century. This underlines the importance of smoking cessation in the prevention of lung cancer, especially since the prognosis of lung cancer remains so depressing, with a 5-yr overall survival rate of $\sim 10 \%$ and without hardly any improvement seen during the last decades [13].

Tobacco use is also the major contributor to COPD. The most important study on the effects of continuing smoking versus stopping on lung function was published in 1976 by FLETCHER et al. [14]. A first study about physician advice to stop smoking was published in a chest clinic as early as 1969 [15]. During the next two decades two well-designed and large studies in British lung clinics, including 4,404 subjects, reported one-year quit rates of $\sim 10 \%[16,17]$. In recent years, the American Lung Health Study, comprising 5,887 patients with mild COPD and published in 1994, was of major importance. Firstly, it showed that stopping smoking compared with continued smoking significantly reduced the age-related decline in forced expiratory volume in one second (FEV1). Secondly, it reported a 5-yr point prevalence of abstinence of $39 \%$, achieved through relatively intensive intervention, initially including weekly smoking cessation sessions during 12 weeks, followed by a relapse prevention programme every 4 months during 5 yrs combined with the use of nicotine chewing gum. The important conclusion from this study is that an aggressive, intensive and repeated smoking cessation programme can produce high long-term quit rates in smokers with mild to moderate airways obstruction [18].

\section{Nicotine addiction is a brain disease}

Cigarette smoking is highly addictive due to the nicotine content. Although the cigarette could merely be considered as a "nicotine delivery system", it delivers so many toxic substances that it should no longer be used for that purpose. Moreover, the tobacco industry has admitted to adding several additives and chemicals to the "natural" tobacco leaves. This process reduces the harshness of the smoke and increases the absorption of nicotine, thus making the cigarette "a better starter product for teenagers".

What the smoker gains from their habit is a positive reward effect, caused by nicotine which activates nicotinergic receptors in the mesolimbic system and the cortex of the brain, resulting in an increase in synaptic dopamine and norephedrine levels, coupled with some genetic predisposition to the likelihood of getting addicted [19]. The possible importance of the 16 different nicotinergic acetylcholine receptors on the presynaptic neurones 
became evident from the study of mutant mice, lacking the $\beta_{2}$ nicotinergic subunit, because these mice do not self-administer nicotine [20]. This opens up the way for new methods in the treatment of "smoking disease" in humans, such as vaccination against smoking. From human experiments in 1945 JOHNSON et al. [21] deduced that nicotine was the agent smokers seek in the cigarette. Since then there have been hundreds of scientific publications on this topic, as summarized in the 1986 report on smoking of the Surgeon General of the USA [22].

\section{Physicians' role and the effect of advice to stop smoking}

For all the reasons stated above smoking cessation is not an easy task. Physicians have to try and convince the individual smoker about the elevated risks of smoking, which are still "relative", since not all of them will develop a disease. All smokers do not easily understand this. In pressing for cessation, a stimulating factor from a not very motivated but heavily addicted subject has to be removed, who beside withdrawal symptoms has to accept a 4-5 kg gain in body weight in an overall environment where "slim line" is the dominant fashion. Therefore, due to these negative factors a $1-y r$ quit rate of $10-20 \%$ is in fact quite encouraging.

In 1996 the European Respiratory Society (ERS) and the American Thoracic Society (ATS) stated that the pulmonary physician had a special obligation to engage in smoking cessation and prevention [23]. Since then several clinical guidelines on achieving this have been published, a large number just recently [24-29]. Smoking cessation is highly cost-effective. Smoking cessation with nicotine replacement therapy (NRT) is $\sim 8$ times more cost-effective per year saved compared to 300 medical treatments [29]. The key recommendation from these guidelines is that every patient should be asked about their smoking habits, advised to quit, assessed for their willingness to make a quit attempt, assisted if they want to quit, and have follow-up visits arranged, i.e. the wellknown five A's [30] (ask about smoking at every opportunity, advise all smokers to stop, assess motivation, assist the patient to stop, arrange for follow-up visits).

With the brief intervention mentioned (lasting 2-3 minutes) a 1 -yr quit rate of $5 \%$ can be attained. Depending on the level of adjunctive behavioural support the success rate will vary. NRT will produce low success rates when used without adjunctive behavioural support. However, since most smokers still quit of their own accord and in many countries they now buy NRT over-the-counter, even these low success rates will have an important impact on public health. The efficacy and cost-effectiveness of NRT in smoking cessation has been extensively documented and the main practical problem today is how to implement smoking cessation in the daily clinical work. Moreover, bupropion, an atypical antidepressive drug, also seems to be at least as effective as NRT and might also be regarded as a first line drug [27]. In two large placebo controlled trials 7-9 weeks of treatment with bupropion combined with moderate counselling doubled the long-term abstinence rates. As bupropion is on prescription it should be looked at as an opportunity to involve clinicians in smoking cessation, although some doctors are reluctant to prescribe NRT or bupropion for their patients who smoke. Candidates for any pharmacotherapy are nicotine dependent smokers, smoking $>10$ cigarettes daily.

It is the authors perception that practical clinical guidelines for smoking cessation, with special focus on the role of the pulmonary specialist, would be welcomed by many members throughout Europe. Also, by developing guidelines with an accreditation system it is believed that the implementation of smoking cessation in our clinics and hospitals might be enhanced. The ERS should have a leading role in this process. P. Tønnesen has initiated a Task Force group in the ERS to produce such clinical recommendations.

\section{Smoke free hospitals}

European pulmonary specialists have recently shown their interest by participating in smoking cessation in the Collaborative European Antismoking Evaluation (CEASE) study, that included 3,575 smokers in 36 centres in 17 European countries and tested the efficacy of nicotine patches and of minimal support, yielding a 1-yr average point prevalence of cessation of $21 \%$ [31]. Pulmonary physicians working clinically should not smoke at work, and should be advocates for smoke free wards and hospitals. Again, Europe can learn from the USA who are years ahead of Europe in the fight against tobacco. Since 1994 standards of the Joint Committee on Accreditation of Healthcare Organisations (JCAHO) has required hospital buildings to be smoke-free. In a large survey of 1,055 US hospitals in 1994 it was found that $>96 \%$ of the hospitals complied with the smoking ban standard and $41 \%$ in fact exceeded the standards. The JCAHO requirements and concerns for the health of the staff were the major forces driving the hospitals "to go smoke-free". The most common barriers to overcome were employees' negative morale and a lack of acceptance by the visitors and patients [32].

\section{Increased research}

Looking ahead realistically to the next 10-20 yrs a smoking prevalence decreasing to $15-20 \%$ in most European countries is suspected. However, considerable harm will still be done. Therefore, a lot more research into less toxic cigarettes and the health effects of snuff use, and also into achieving a gradual down-regulation of the tar and other toxic product delivery in cigarettes is advocated. Methods other than the unreliable machine smoked set-ups should be used to assess the tar delivery from cigarettes. This research should be supported by grants originating from an annually increasing per cent of the cigarette tax and supplemented by money from a voluntary settlement between the European Union and the Tobacco Companies.

To conclude, reduced exposure to tobacco and its reduced uses are key elements in the prevention of morbidity and mortality of people all over the world. The European Respiratory Society and the individual pulmonary specialist in Europe must play a key role in this process during the next few decades, in close association with other medical organizations, governmental and nongovernmental organizations and, last but not least, politicians! 


\section{References}

1. Reviews. BMJ 2000; 321: 308-392.

2. Tobacco. JAMA 2000; 284: 659-794.

3. Framework Convention on Tobacco Control: fifty-third World Health Assembly: Report of the Working Group. Geneva, Switzerland: World Health Organization; 2000. Report A53/12;A53/12 Corr.1.

4. Jha P, Chaloupka FJ. The economics of global tobacco control. BMJ 2000; 321: 358-361.

5. Farkas AJ, Gilpin EA, White MM, Pierce JP. Association between household and workplace smoking restrictions and adolescent smoking. JAMA 2000; 284: 717-722.

6. Wakefield MA, Chaloupka FJ, Kaufman NJ, Orleans CT, Barker DC, Ruel EE. Effect of restrictions on smoking at home, at school, and in public places on teenage smoking: cross sectional study. BMJ 2000; 321: 333-337.

7. Bauer UE, Johnson TM, Hopkins RS, Brooks RG. Changes in youth cigarette use and intentions following implementation of a tobacco control programme. JAMA 2000; 284: 723-728.

8. Wakefield M, Chaloupka E. Effectiveness of comprehensive tobacco control programmes in reducing teenage smoking in the USA. Tob Control 2000; 9: 177-186.

9. Biener L, Harris JE, Hamilton W. Impact of the Massachusetts tobacco control programme: population based trend analysis. BMJ 2000; 321: 351-354.

10. Levin ML, Goldstein H, Gerhardt PR. Cancer and tobacco smoking: a preliminary report. JAMA 1950; 143: 336-338.

11. Wynder EL, Graham EA. Tobacco smoking as a possible etiologic factor in bronchiogenic carcinoma. JAMA 1950; 143: 329-336.

12. Doll R, Peto R, Wheatley K, Gray R, Sutherland I. Mortality in relation to smoking: 40 years' observation on male British doctors. BMJ 1994; 309: 901-911.

13. Peto R, Darby S, Deo H, Silcocks P, Whitley E, Doll R. Smoking, smoking cessation and lung cancer mortality in the UK since 1950: combination of national statistics with two case-control studies. BMJ 2000; 321: 323-329.

14. Fletcher C, Peto R, Tinker C, et al. The natural history of chronic bronchitis and emphysema. Oxford, Oxford University Press, 1976.

15. Williams HO. Routine advice against smoking. A chest clinic pilot study. Practitioner 1969; 202: 672-676.

16. British Thoracic Society. Comparison of four methods of smoking withdrawal in patients with smoking related diseases. BMJ 1983; 286: 595-597.

17. Research Committee of the British Thoracic Society. Smoking cessation in patients: two further studies by the British Thoracic Society. Thorax 1990; 45: 835-840.

18. Anthonisen NR, Connett JE, Kiley JP, et al. Effects of smoking intervention and the use of an inhaled anticholinergic bronchodilator on the rate of decline of FEV1. The Lung Health Study. J Am Med Assoc 1994; 272: $1497-1505$.

19. Watkins SS, Koob GF, Markou A. Neural mechanisms underlying nicotine addiction: acute positive reinforcement and withdrawal. Nicotine Tob Res 2000; 2: 19-37.
20. Picciotto MR, Zoli M, Rimondini R, et al. Acetylcholine receptors containing the beta2 subunit are involved in the reinforcing properties of nicotine. Nature 1998; 391: 173177.

21. Johnston LM, Glasg MB. Tobacco smoking and nicotine. Lancet 1942; 240: 742

22. U.S. Department of Health and Human Services. The health consequences of smoking: nicotine addiction. Rockville, MD. A report of the Surgeon General. U.S. Department of health and Human Services, 1986.

23. American College of Chest Physicians, American Thoracic Society, Asia Pacific Society of Respirology, Canadian Thoracic Society, European Respiratory Society International Union Against Tuberculosis and Lung Diseases. Smoking and Health: A Physicians responsibility. A statement of the joint committee on smoking and health. Eur Respir J 1995; 8: 1808-1811.

24. Raw M, McNeill A, West R. Smoking cessation guidelines for health professionals: a guide to effective smoking cessation interventions for the health care system. Thorax 1998; 53: S1-S19.

25. Lancaster T, Stead L, Silagy C, Sowden A, for the Cochrane Tobacco Addiction Review Group. Effectiveness of interventions to help people to stop smoking: findings from the Cochrane Library. BMJ 2000; 321: 355-358.

26. Consensus statement: a clinical practice guideline for treating tobacco use and dependence, a US Public Health Service Report. JAMA 2000; 283: 3244-3254.

27. Fiore MC, Bailey MC, Cohen SJ, et al. Treating tobacco use and dependence. Clinical practice guideline. Rockville, MD: Public Health Service, 2000. AHRQ publication no 00-0032.

28. US Department of Health and Human Services. Reducing tobacco use. A report of the Surgeon General. Atlanta, Georgia: US Department of Health and Human Services, Centers for disease control and prevention, National center for chronic disease prevention and health promotion, Office on smoking and health, 2000.

29. Nicotine addiction in Britain: A report of the tobacco advisory group of the royal college of physicians. London, England, Royal College of Physicians, 2000; pp. $15-20$.

30. Glynn TJ, Manley MW. How to help your patients to stop smoking: A National Cancer Institute Manual for Physicians. Bethesda, MD: US Department of Health and Human Services, Public Health Service, National Institute of Health, National Cancer Institute, 1993. NIH Publication No. 93-3064.

31. Tønnesen P, Paoletti P, Gustavsson G, et al, members of the steering committee of CEASE on behalf of the European Respiratory Society. Higher dosage nicotine patches increase one-year smoking cessation rates: results from the European CEASE trial. Eur Respir J 1999; 13: 238-246.

32. Longo DR, Feldman MM, Kruse RL, Brownson RC, Petroski GF, Hewett JE. Implementing smoking bans in American hospitals: results of a national survey. $T o b$ Control 1998; 7: 47-55. 